\title{
Anticardiolipin Antibody Isotype Determination in Amniotic Fluid of Pregnant Patients with Systemic Lupus Erythematosus and/or Antiphospholipid Syndrome
}

\author{
Xibillé-Friedmann Daniel ${ }^{*}$, Sánchez-Rodríguez Carmen², Cruz-Cruz Polita ${ }^{3}$, \\ García de la Torre Ignacio ${ }^{4}$, Jara-Quezada Luis Javier ${ }^{5}$ \\ ${ }^{1}$ Departamento de Reumatología, Hospital General de Cuernavaca “Dr. José G. Parres”, Servicios de Salud de \\ Morelos, Cuernavaca, Morelos, México \\ ${ }^{2}$ Ginecología y Obstetricia, Torre Médica San Diego, Cuernavaca, Morelos, México \\ ${ }^{3}$ Departamento de Perinatología, Hospital de Ginecoobstetricia 3, Centro Médico Nacional La Raza, Instituto \\ Mexicano del Seguro Social, México, Distrito Federal, México \\ ${ }^{4}$ Hospital General de Occidente, SS, Guadalajara, Jalisco, México \\ ${ }^{5}$ División de Investigación, Hospital de Especialidades, Centro Médico Nacional La Raza, Instituto Mexicano del \\ Seguro Social, México, Distrito Federal, México \\ Email: ${ }^{*}$ daniel.xibille@uaem.mx
}

Received 28 May 2014; revised 28 June 2014; accepted 28 July 2014

Copyright (C) 2014 by authors and Scientific Research Publishing Inc.

This work is licensed under the Creative Commons Attribution International License (CC BY).

http://creativecommons.org/licenses/by/4.0/

c) (i) Open Access

\begin{abstract}
Objective: To determine the levels and isotypes of $\mathrm{aCl}$, as well as anti beta 2 glycoprotein 1 (antiß2GP1) antibodies in serum and amniotic fluid of pregnant patients with SLE and/or APLS, and healthy pregnant women serving as a control group. Material and Methods: We analyzed serum and amniotic fluid of pregnant patients with SLE and/or APLS, and of healthy pregnant women through ELISA. Results were compared using a Student's T test. Results: 6 of 13 patients (46.1\%), 5 with SLE and one with primary APLS had antiphospholipid antibodies in amniotic fluid. Two patients had IgG aCl and 4 patients had antiß2-GP1 (one of them also showing IgM) in amniotic fluid. In serum, 4 patients $(30 \%)$ had antiphospholipid antibodies present (one IgG aCl and three anti $\beta 2-G P 1)$ as opposed to none in the control group having antiphospholipid antibodies in amniotic fluid. Only one control had IgM aCl in serum. Antiß2-GP1 in the amniotic fluid of patients showed a statistically significant value when compared to controls. Conclusion: aCl and antiß2-GP1 may be present in the amniotic fluid of patients with and without a history of fetal loss. The presence of
\end{abstract}

*Corresponding author.

How to cite this paper: Daniel, X.-F., et al. (2014) Anticardiolipin Antibody Isotype Determination in Amniotic Fluid of Pregnant Patients with Systemic Lupus Erythematosus and/or Antiphospholipid Syndrome. Open Journal of Rheumatology and Autoimmune Diseases, 4, 170-177. http://dx.doi.org/10.4236/ojra.2014.43024 
IgM $\mathrm{aCl}$ and antiß2-GP1 in amniotic fluid suggests its localized production.

\title{
Keywords
}

\author{
Antiphospholipid Syndrome, Systemic Lupus Erythematosus, Pregnancy, Amniotic Fluid
}

\section{Background}

The presence of anticardiolipin antibodies $(\mathrm{aCl})$ in maternal serum has been linked with recurrent fetal loss and adverse neonatal outcomes such as intrauterine growth retardation. These complications are associated to placental insufficiency and seem to be the consequence of the interaction between antiphospholipid antibodies and the placental tissue [1].

Among the resulting damage inflicted by these antibodies are decidual vasculopathy, placental vessel thrombosis and placental infarction [2]. It has been suggested [3] that $\mathrm{aCl}$ are responsible for intrauterine stroke or neonatal convulsions [4]. These authors have suggested that immunoglobulin G (IgG) crosses the placental barrier and reaches the fetal circulation and can be the cause of thrombosis in the fetus.

The presence of maternal $\mathrm{aCl}$ in amniotic fluid (AF) and umbilical cord blood of babies whose mothers have antiphospholipid antibody syndrome has been demonstrated (APS) [5], although no other antibodies are documented, for instance anti beta 2 glycoprotein 1 (antiß2-GP1) antibodies, a protein that is importantly involved in the pathogenesis of APS.

Other authors [6] have not found complications arising from the presence of these antibodies in the products of mothers with APS. By studying the isotypes of aCL and searching for anti $\beta 2$-GP1 the pathogenic mechanisms that lead to the elevated perinatal morbidity of patients with these antibodies during pregnancy (patients with Systemic Lupus Erythematosus SLE or APS) may be further elucidated.

The objective of this study was to determine the levels and isotype of aCL as well as anti $\beta 2-G P 1$ in serum and AF of pregnant patients with SLE and/or APS, comparing them to a control population.

\section{Material and Methods}

We performed a case-control study in which we obtained at least two and up to five serum and AF samples from pregnant patients with SLE, APS, or both, classified according to the American Rheumatology Association [7] criteria and the APS [7] 1997 criteria respectively (which require both a clinical as well as a biochemical criterion in order to be adequately classified), with a gestational age between 14 and 38 weeks. As a control group we obtained the sera and AF samples from a group of healthy pregnant women with similar demographic characteristics, matched for age in order to reduce bias.

All patients were receiving attention at the Clinic for Rheumatic Disease and Pregnancy at the department of Rheumatology Centro Médico Nacional La Raza. At the clinic we performed a clinical history of each patient, a detailed physical exploration, as well as making sure that an experienced perinatologist at the hospital obstetrics department follows every patient. During pregnancy patients are evaluated every four weeks and once after the obstetric event. During each visit we perform routine laboratory tests (complete blood count, blood chemistry and urine exam) as well as those laboratory tests that are deemed necessary according to each case.

The patients past medical history, family history and obstetrical history as well as the length of SLE or APS and its disease activity status and treatment are determined and reviewed during each patient visit, with data included into the patient file databank.

Alter obtaining informed consent we drew serum samples by peripheral vein puncture. After centrifuging, the serum samples were frozen at $-70^{\circ} \mathrm{C}$. Determination of aCL (IgG and IgM isotypes) as well as anti $\beta 2$-GP1 (IgG) in serum and AF was performed by indirect ELISA (Santa Cruz Biotech, CA, USA) at a central laboratory by one of the researchers (IGT). Briefly, indirect ELISA consists of a buffered solution with a specific antigen bound to a microtiter plate to which the problem sera (and in our case, AF) is added, binding to the antigen, and then a secondary antibody is added which binds to the problem antibody, revealing it by means of an enzymatic reaction.

AF was obtained through an ultrasound-guided amnioscentesis, using a sterile technique, by one of the researchers (CS), a board-certified obstetrician training in perinatology. Samples were stored at $-70^{\circ}$ until pro- 
cessing. There were no complications due to the procedure. In the case of control AF samples, most were obtained by amniotomy performed previous to the cesarean section by the obstetrician, maintaining a sterile technique, and also stored at $-70^{\circ}$. It must be mentioned that all cesarean sections in controls were performed due to obstetric indications and were elective. Once all samples were collected, these were also analyzed using indirect ELISA at the central laboratory. Both in the case of serum as in the case of amniotic fluid, samples were transported maintaining a cold-chain through the use of dry ice. Assays, both for sera as well as AF, were all performed in triplicate.

The reference values used were the following: Serum, aCl IgG >15 GPL, aCl IgM $>12.5$ MPL and anti $\beta 2-$ GPI $<20$ UI, AF, aCl IgG $>23$ GPL, aCl IgM $>11$ MPL, anti $\beta 2$ GPI $<20$ UI. The former are based on the standardized reference values used by our laboratory and the latter were established in an arbitrary manner.

The hospital ethics board reviewed and approved the study protocol prior to its execution. The sample size was established by convenience due to the difficulty in obtaining amniotic fluid samples from patients. Descriptive statistical analysis was employed. Although the design was that of a case-control study, we determined means and Standard Deviations of the different variables, and applied the Student T's test for the comparison of the results obtained between patients and control subjects. A value of $p$ equal or under 0.005 was considered significant.

\section{Results}

A total of 28 samples of each serum and amniotic fluid were analyzed, obtained from 13 patients (10 with SLE and 3 with APS) as well as 15 controls. The characteristics of patients are show on Table 1.

Patients with PAPS did not have any thrombotic or obstetric problems during their pregnancy. Eleven patients had a cesarean section, the indication being preeclampsia in 2 of them, previous cesarean section in 2, cephalopelvic disproportion in 2, premature membrane rupture in 2, fetal hypomotility in one, circular umbilical cord in 1 , acute fetal distress in one and no clear indication in another. All controls underwent a cesarean section because of obstetric or elective motives. The levels and isotypes of aCL, both in serum as in amniotic fluid of patients with rheumatic disease and of controls are shown in Table 2. The levels of anti $\beta 2$-GP1 in serum and amniotic fluid of patients and controls are shown in Table 3. Table 4 compares antibody titers between patients and controls.

Table 1. General characteristics of patients and controls.

\begin{tabular}{ccc}
\hline Characteristic & Patients & Controls \\
\hline Age & $28.8 \pm 7.6(\mathrm{r}=20-42)$ & $28.4 \pm 7.5(\mathrm{r}=21-38)$ \\
SLE activity & 6 patients & NA \\
Gestational age at sampling & $24.8 \pm 7.4(\mathrm{r}=14-36)$ & $38.7 \pm(\mathrm{r}=38-40)$ \\
Gestational age at birth & $37.2 \pm 1.9(\mathrm{r}=32-39)$ & $38.7 \pm 0.70(\mathrm{r}=38-40)$ \\
Mode of pregnancy termination & 2 Natural birth, 11 Cesarean section & 15 Cesarean section \\
Previous fetal loss & 5 & 1 \\
\hline
\end{tabular}

Table 2. Levels and isotypes of aCL in patients and controls.

\begin{tabular}{ccccccccc}
\hline & \multicolumn{2}{c}{ Patient sera } & \multicolumn{2}{c}{ Patient AF } & \multicolumn{2}{c}{ Control sera } & \multicolumn{2}{c}{ Control AF } \\
\cline { 2 - 9 } & IgG & IgM & IgG & IgM & IgG & IgM & IgG & IgM \\
\hline 1 & 13.2 & 9.6 & 8.7 & 0.9 & 12.8 & 11 & 8 & 1.3 \\
2 & 4.4 & 9.3 & 11 & 1.13 & 12.7 & 17 & 5 & 1 \\
3 & 4.7 & 10 & 8 & 0.4 & 14.9 & 11.2 & 12.4 & 0.5 \\
4 & 11.9 & 8.2 & 12 & 0.7 & 8.3 & 6.3 & 9.4 & 1 \\
5 & 7.5 & 3.9 & 11 & 0.4 & 11.6 & 4.1 & 5.6 & 1.1 \\
6 & 6.1 & 9.2 & 7.8 & 1.3 & 12.1 & 10.2 & 5.3 & 1.2 \\
7 & 8 & 4.7 & 3.4 & 0.4 & 30.9 & 5.9 & 10.7 & 2.1 \\
8 & 1 & 0.7 & 7.5 & 0.4 & 4.4 & 3.3 & 6.3 & 1.3 \\
9 & 10.3 & 7.4 & 40.5 & 35.1 & 7.2 & 4.5 & 11.9 & 9.6 \\
10 & 10.8 & 3.4 & 7.2 & 0.7 & 8.1 & 7.3 & 9.8 & 1.5 \\
11 & 10.8 & 14.1 & 14.1 & 0.68 & 5.8 & 7 & 4.1 & 1 \\
12 & 1 & 17.1 & 17.1 & 0.5 & 6.5 & 7.2 & 7.1 & 1.1 \\
13 & 9.1 & 13.1 & 13.1 & 3.2 & 5.8 & 5.1 & 18.8 & 0.5 \\
\hline
\end{tabular}


Table 3. Level of anti- $\beta 2$ glicoproteína 1 (IgG) antibodies in patients and controls.

\begin{tabular}{ccccc}
\hline & Patient sera & Patient AF & Control sera & Control AF \\
\hline 1 & 107 & 79.4 & 2.1 & 3.8 \\
2 & 25.5 & 20 & 1.1 & 2.1 \\
3 & 7.7 & 20 & 1.2 & 2.6 \\
4 & 1.4 & 10.4 & 1.8 & 3.7 \\
5 & 6.6 & 8 & 1.1 & 4.2 \\
6 & 4.1 & 11.8 & 2 & 2 \\
7 & 12.5 & 16.5 & 1.8 & 6.3 \\
8 & 16.7 & 12 & 1.5 & 3.6 \\
9 & 11.5 & 11.5 & 1.3 & 3.8 \\
10 & 25.9 & 5.6 & 1.5 & 4.5 \\
11 & 10.8 & 5.3 & 2 & 4 \\
12 & 3.4 & 11.5 & 2 & 2.5 \\
13 & 2 & 57.8 & 2.4 & 13.9 \\
\hline
\end{tabular}

Table 4. Comparison in antibody levels between patients and controls.

\begin{tabular}{cccc}
\hline & Patients $(\mathbf{n}=\mathbf{1 3})$ & Controls $(\mathbf{n}=\mathbf{1 5})$ & $\boldsymbol{p}$ \\
\hline Serum aCl IgG & $7.6 \pm 3.9$ & $9.5 \pm 7.2$ & 0.23 \\
Serum aCl IgM & $6.0 \pm 3.7$ & $6.7 \pm 4.2$ & 0.78 \\
Serum Anti $\beta 2-G P 1$ & $18.0 \pm 27.8$ & $1.8 \pm 0.5$ & 0.01 \\
AF aCl IgG & $12.4 \pm 9.1$ & $9.8 \pm 5.5$ & 0.48 \\
AF aCl IgM & $3.5 \pm 9.5$ & $2.3 \pm 3.3$ & 0.23 \\
AF Anti $\beta 2-G P 1$ & $20.9 \pm 22.0$ & $4.6 \pm 2.9$ & 0.005 \\
\hline
\end{tabular}

Two of the patients that had positive anti $\beta 2-G P 1$ antibodies in AF had a previous fetal loss. Of the 13 patients, 8 had a preterm delivery (37 weeks or less), although all of the babies survived. Figure 1 and Figure 2 show the aCL IgG levels in sera and AF respectively, as well as a comparison between patients and controls.

Figure 3 and Figure 4 compare the levels of aCL IgM in sera and AF respectively, between patients and controls. It is noteworthy that, in the case of $\operatorname{IgM~aCl}$, one patient showed an abnormally high titer. Figure 5 and Figure 6 show the comparison between the levels of anti $\beta 2-G P 1$ in sera and AF respectively, again comparing patients with controls. In Table 4 we summarize the comparisons between patients and controls with respect to the levels of aCl and anti $\beta 2-\mathrm{GP} 1$, showing the statistical significance ( $p$ value) that each comparison attained.

\section{Discussion}

This study describes for the first time the presence of IgG and IgM aCl as well as anti $\beta 2-G P 1$ IgG, in the amniotic fluid of patients with SLE or APS. Among six of the thirteen patients (46.1\%), 5 with SLE and one with PAPS had antiphospholipid antibodies in their amniotic fluid. Two patients had IgG aCl and 4 patients had anti $\beta 2-G P 1$ (one of them also had aCl IgM) in the AF. In the sera, 4 patients (30\%) had positive levels of antiphospholipid antibodies ( 3 anti $\beta 2-G P 1$ and 1 aCl IgG). In contrast, none of the controls had antiphospholipid antibodies in the AF. Only one control had a positive serum aCl IgM. The presence of anti $\beta 2-\mathrm{GP} 1$ in the AF of patients reached a statistical significance when compared to controls.

Two of the patients that had these antibodies in the AF had a previous history of fetal loss, although fortunately during the present pregnancy none had obstetrical complications. These results suggest that the antiphospholipid antibodies, especially anti $\beta 2-G P 1$ (IgG) cross the placental barrier. The presence of IgM aCl and anti $\beta 2-G P 1$ in the AF with a negative serum value in the same patient suggest local synthesis of these antibodies [3] [4]. The mechanism that permits the passage of IgG through the placentae has been described as active transport by means of endocytosis, thus explaining why aCL can be found both in the sera and in the AF of these patients [5]. Only one study found 54.5\% positivity for IgG in AF and 27.3\% in the cord blood of patients with 


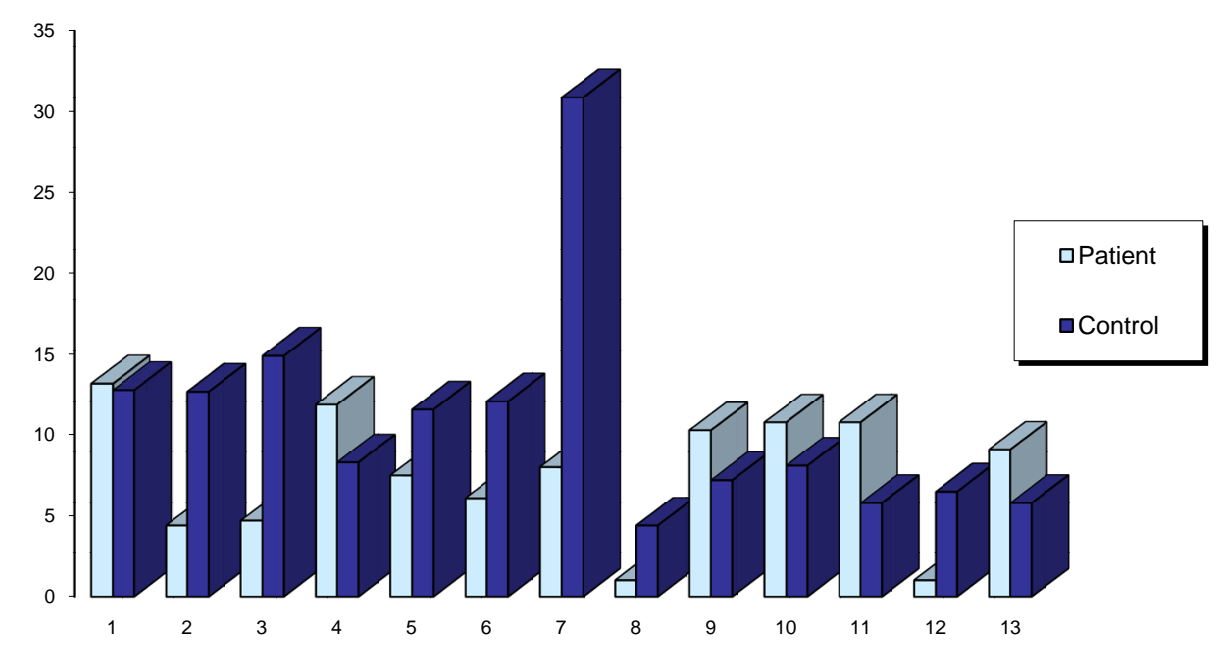

Figure 1. Serum IgG aCl (GPL units) of patients with SLE/PAPS vs. controls.

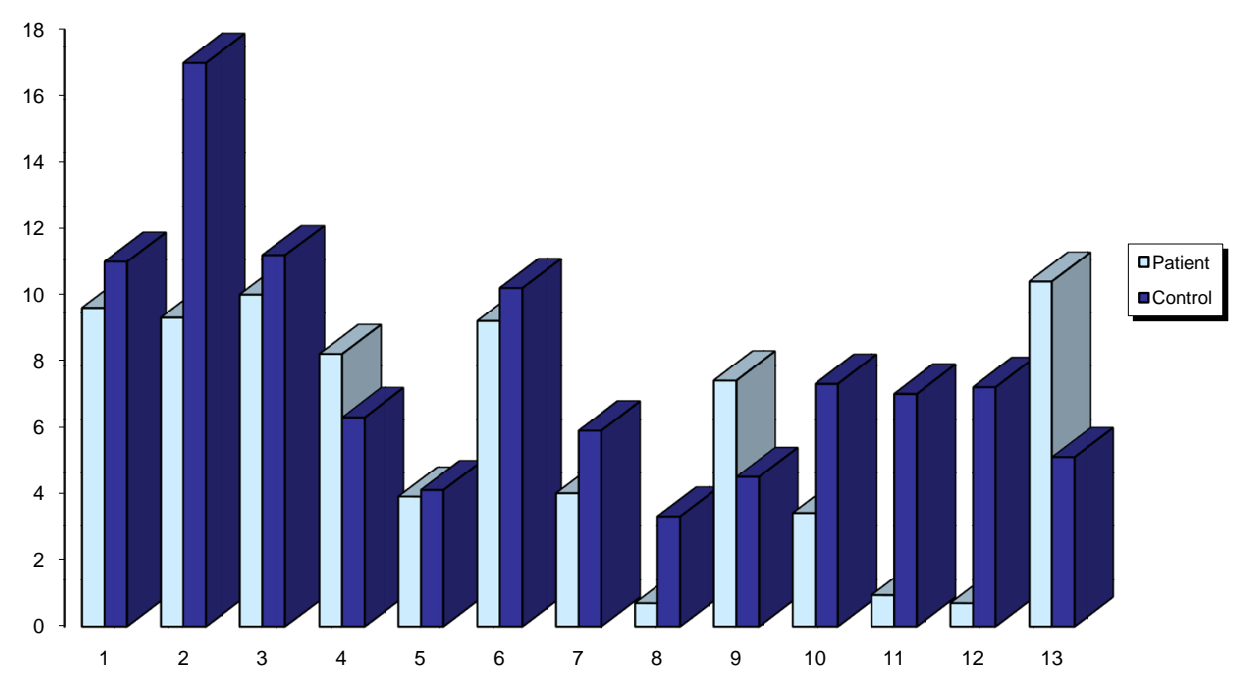

Figure 2. Serum IgM aCl (MPL units) of patients with SLE/PAPS vs. controls.

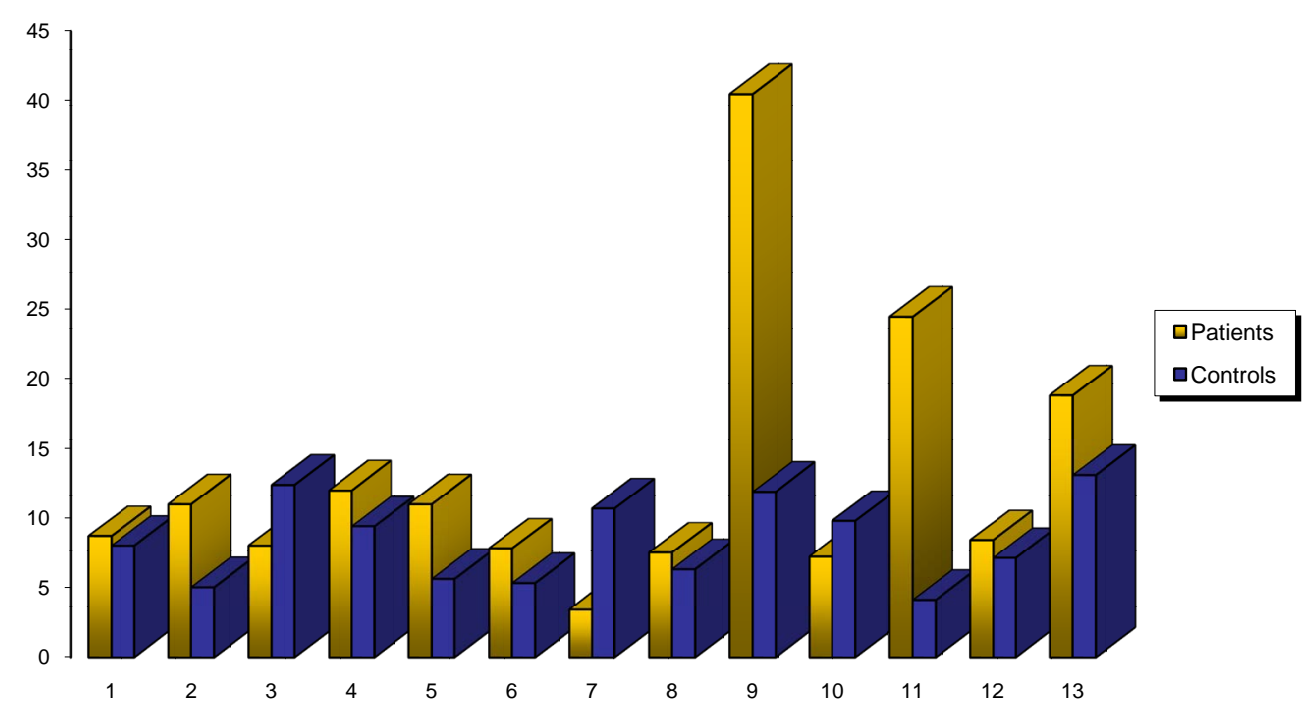

Figure 3. AF IgG aCl (GPL units) of patients with SLE/PAPS vs. controls. 


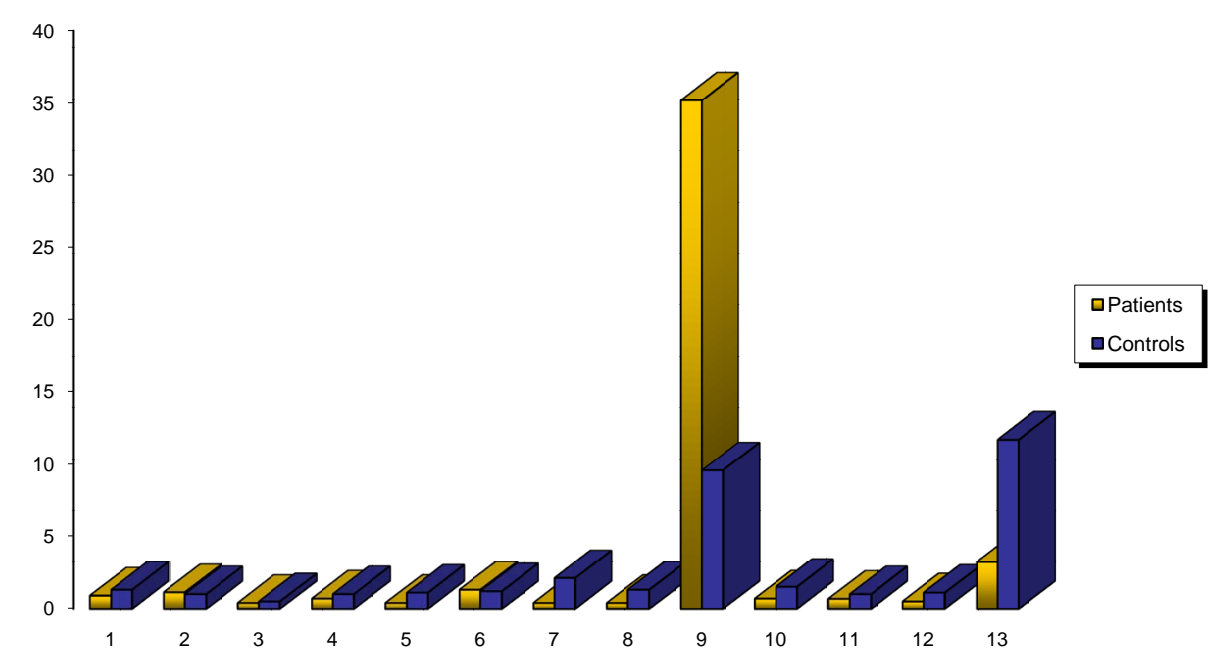

Figure 4. AF IgM aCl (MPL units) of patients with SLE/PAPS vs. controls.

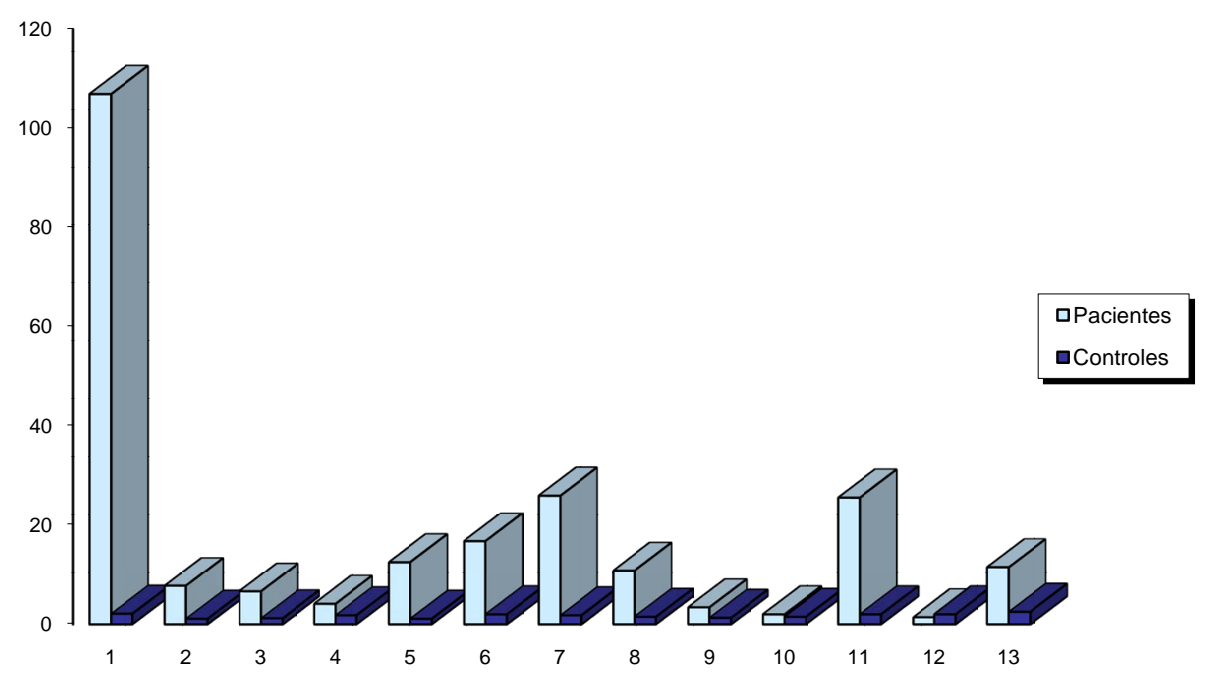

Figure 5. Serum anti $\beta 2-G P 1$ (IU) of patients with SLE/PAPS vs. controls.

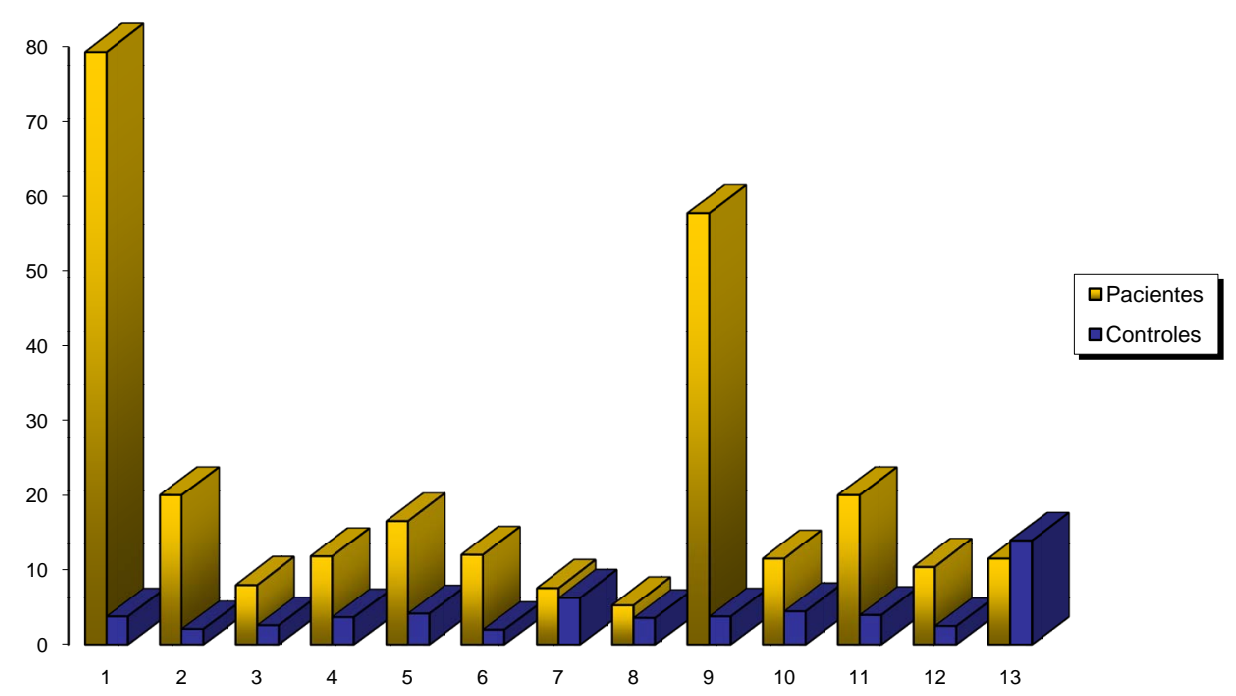

Figure 6. AF anti $\beta 2-\mathrm{GP} 1$ (IU) of patients with SLE/PAPS vs. controls. 
APS. Nonetheless the aforementioned study did not mention if other isotypes of Ig were found or other antibodies involved in the pathogenesis of fetal loss that accompanied SLE/APS. In the present study we did not find a correlation between the serum levels of aCL and their presence in significant amounts in the AF. The meaning of these findings is unknown although it is possible that aCL and anti $\beta 2$-GP1 play a pathogenic role in the fetal loss that accompanies these diseases, as has been described [3] [4]. One possibility is that these antibodies form locally due to a stimuli from the trophoblastic phospholipids (also known as aminophospholipids) [8]. These locally produced antibodies could interact with Annexin V, a placental anticoagulant protein and lead to thrombosis.

The presence of IgM aCL in the AF of patients with SLE/APS has not been previously described, and is probable due to local production, as IgM cannot cross the placental barrier. The clinical meaning of this finding is uncertain and more study is needed to clarify it.

Antiß2-GP1 antibodies in the AF of patients with SLE/APS probable originate in the maternal circulation (as it is IgG). These antibodies play an important role in pathogenesis of thrombosis in APS, but their role in the fetal microenvironment as related to fetal morbidity and mortality is still uncertain. Experimental models show that these antibodies can be deposited in the placentae, leading to intrauterine growth retardation and placental necrosis [9] recently associated with fetal loss. APL antibodies have also been found in tissues such as cerebrospinal fluid [10].

The limitations of our work are mainly the small number of patients studied and the lack of standardization in the AF APL detection techniques. This also makes statistical analysis difficult, albeit this was not primarily a part of the design, as it was, from the onset, deemed a case-control study. In the case of serum IgM aCl, controls tended to present higher titers than cases, something that we believe seems to be associated with their lack of specificity in relation to the accompanying clinical manifestations of APS [11]. In the case of IgM aCl in AF, the difference between groups seems to hinge on a single outlier value, another limitation in our analysis, as it makes this finding questionable. On the other hand we relieve the results are trustworthy due to the fact that no control (normal) pregnancy has levels of APL in their AF over the established baseline.

There is little study of the amniotic environment in the pregnancies of patients with SLE and APS due to the challenges and constrains that both diseases present to patients and physicians alike. Although our study has important limitations, making the drawing of conclusions limited, it provides an insight into the local conditions that affect pregnancy outcome in these patients.

\section{Conclusion}

In conclusion, both $\mathrm{aCl}$ and anti- $\beta 2-\mathrm{GP} 1$ can be found in the AF of patients with or without a history of fetal loss; the presence of aCl IgM and anti- $\beta 2-\mathrm{GP} 1$ in AF suggests trans-placental transfer and/or local production and AF $\mathrm{aCl}$, and anti $\beta 2-\mathrm{GP} 1$ cut-off value standardization is needed in order to better study this phenomenon.

\section{References}

[1] Branch, D., Scott, J., Kochenour, N. and Hershgold, E. (1985) Obstetric Complications Associated with the Lupus Anticoagulant, The New England Journal of Medicine, 313, 1322-1326. http://dx.doi.org/10.1056/NEJM198511213132104

[2] Love, P. and Stantoro, S. (1990) Antiphospholipid Antibodies: Anticardiolipin and the Lupus Anticoagulant in Systemic Lupus Erythematosus (SLE) and Non-SLE Disorders. Annals of Internal Medicine, 11, 682-688. http://dx.doi.org/10.7326/0003-4819-112-9-682

[3] Silver, R., MacGregor, S. and Pasternak, J. (1992) Neely S, Fetal Stroke Associated with Elevated Maternal Anticardiolipin Antibodies. Obstetrics and Gynecology, 880, 497-499.

[4] De Klerk, O., De Vries, T. and Sinnige, L. (1997) An Unusual Case of Neonatal Seizures in a New Born Infant. Pediatrics, 100, E8. http://dx.doi.org/10.1542/peds.100.4.e8

[5] Cohen, S., Goldenberg, M., Rabinovici, J., Lidor., A., et al. (1999) Anticardiolipin Antibodies in Fetal Blood and Amniotic Fluid From Patients with the Antiphospholipid Syndrome. Human Reproduction, 15, 1170-1172. http://dx.doi.org/10.1093/humrep/15.5.1170

[6] Botet, F., Romera, G., Montagut, P., et al. (1997) Neonatal Outcome in Women Treated for Antiphospholipid Syndrome during Pregnancy. Journal of Perinatal Medicine, 23, 192-196. http://dx.doi.org/10.1515/jpme.1997.25.2.192

[7] Ramos Niembro F. (1999) Lupus eritematoso generalizado, y síndrome antifosfolípido. En: Enfermedades Reumáticas: 
clasificación y diagnóstico, $1^{\text {a }}$ ed, Mc Graw-Hill Interamericana, México.

[8] Cowchock, F., Reece, E., Balaban, D., Branco, D., et al. (1992) Repeated Fetal Losses Associated with Antiphospholipid Antibodies: A Collaborative Randomized Trial Comparing Prednisone to Low-Dose Heparin Treatment. American Journal of Obstetrics \& Gynecology, 166, 1318-1323. http://dx.doi.org/10.1016/0002-9378(92)91596-3

[9] Holers, V., Girardi, G., Mo. L., et al. (2002) Complement C3 Activation Is Required for Antiphospholipid Antibody Induced Fetal Loss. The Journal of Experimental Medicine, 195, 211-220. http://dx.doi.org/10.1084/jem.200116116

[10] Lai, N. and Lan, J. (2000) Evaluation of Cerebrospinal Anticardiolipin Antibodies in Lupus Patients with Neuropsychiatric Manifestations. Lupus, 9, 353-357. http://dx.doi.org/10.1191/096120300678828415

[11] Geis, W. and Branch, D.W. (2001) Obstetric Implications of Antiphospholipid Antibodies: Pregnancy Loss and Other Complications. Clinical Obstetrics \& Gynecology, 44, 2-10. http://dx.doi.org/10.1097/00003081-200103000-00002 
Scientific Research Publishing (SCIRP) is one of the largest Open Access journal publishers. It is currently publishing more than 200 open access, online, peer-reviewed journals covering a wide range of academic disciplines. SCIRP serves the worldwide academic communities and contributes to the progress and application of science with its publication.

Other selected journals from SCIRP are listed as below. Submit your manuscript to us via either submit@scirp.org or Online Submission Portal.
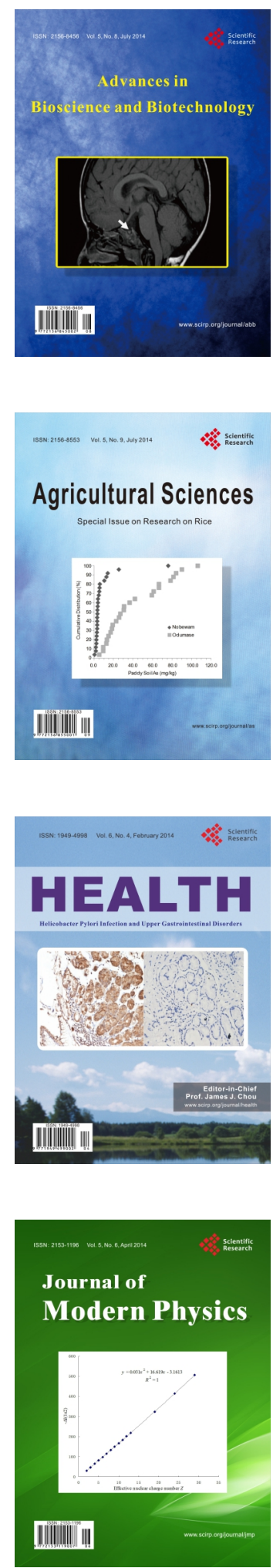
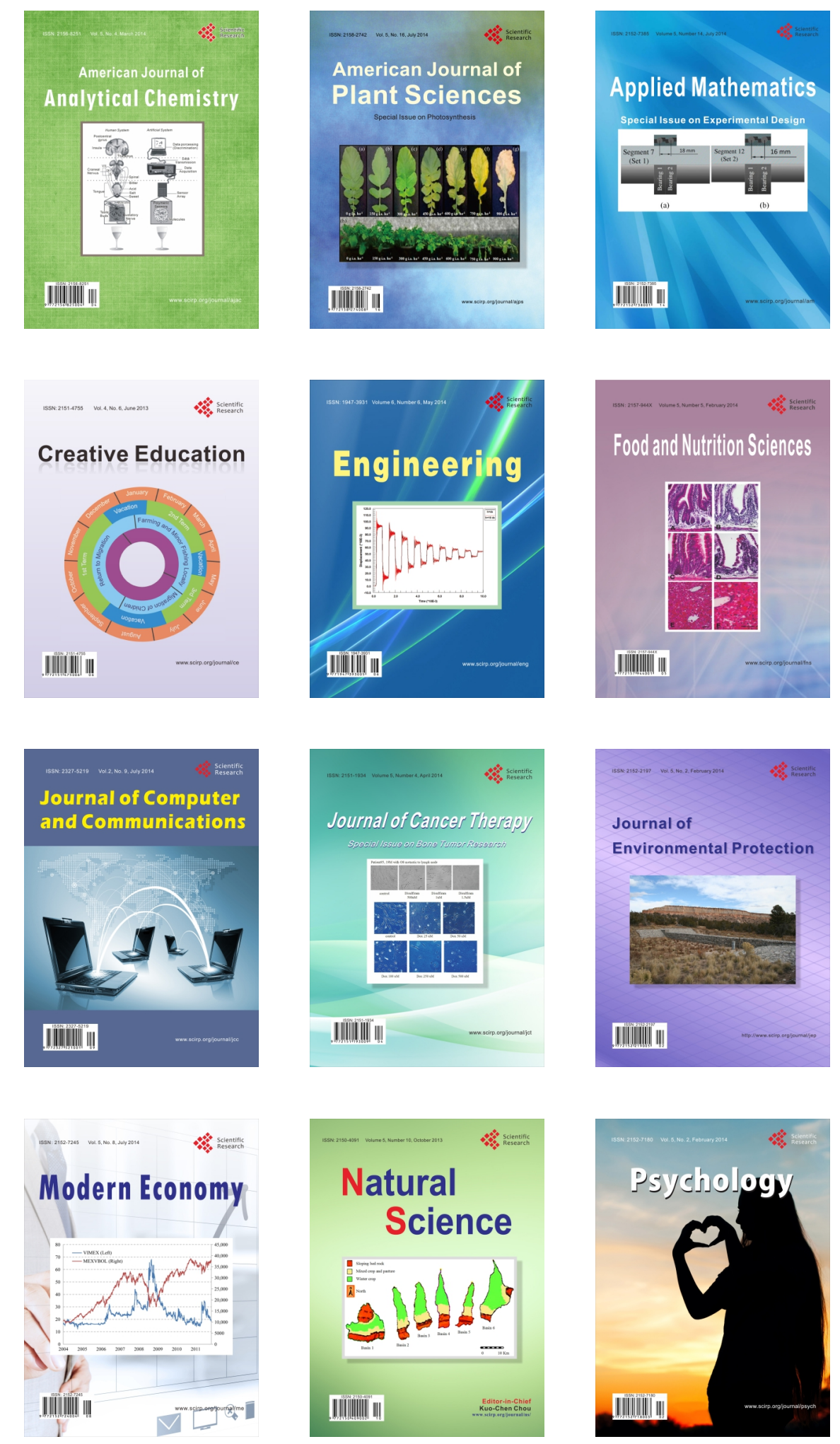